\title{
Post-Traumatic Stress Disorder: The Case of Nekemte Town Correctional Center, West Ethiopia
}

\author{
Shimelis Girma ${ }^{1 *}$, Teshale Fikadu ${ }^{2}$ and Bekuma Tadesse ${ }^{3}$ \\ ${ }^{1}$ Department of Psychiatry, Institute of Health, Jimma University, Ethiopia \\ ${ }^{2}$ Department of Public Health, Arba Minch University, Ethiopia
}

${ }^{3}$ College of Health Sciences, Nekemte College of Health Sciences, Ethiopia

\begin{abstract}
Background: Post traumatic stress disorder (PTSD) is one of the psychiatric disorders leading to the widest use of health care systems in prisoners. However, in Ethiopia, there is no evidence regarding the magnitude and associated factors among the prisoners. Thus, this study was designed to assess the prevalence of post-traumatic stress disorder and associated factors among prisoners of Nekemte town correctional center, West Ethiopia, 2017.

Method: Institutional-based cross-sectional study was conducted from June 1-26, 2017 in Nekemte town correctional center. Three hundred thirty two prisoners were randomly selected by using simple random sampling technique. Socio- demographic and related data was collected by using structured interviewer administered questionnaire. PTSD was assessed by using PTSD Checklist - Civilian Version (PCL-C). Data entry was done by Epi data version 3.1 and analysis was done by SPSS 21.0 statistical software.

Result: Finding of this study indicated that the prevalence of PTSD was $31 \%$. Regarding the characteristics of study population, $93.7 \%$ of participants were male whose age ranged from 16 to- 84 year. In the final multiple logistic regression model, age group 37-50 [AOR=2.82 (95\% Cl: 1.31, 6.06)], single [AOR=1.86 (95\% Cl: 1.06, 3.27)], migration history $[\mathrm{AOR}=4.5(95 \% \mathrm{Cl}: 2.45,8.19)]$ and duration of sentence $19-43$ months $[\mathrm{AOR}=0.49(95 \% \mathrm{Cl}$ : 0.27-0.94)] were statistically significantly associated with PTSD.

Conclusion: This study found out, one third of prisoners had PTSD. Age 37-50, single, migration history and duration of Sentence 19-43 months had significant association with PTSD. Concerned bodies need to establish and strengthen care and support for the inmate.
\end{abstract}

Keywords: Post Traumatic stress disorder; Nekemte; Prisoners

\section{Introduction}

The prevalence of poor mental health among prisoners is considerably higher than in the community, and studies worldwide have shown that suicide rates in prisons are up to 10 times higher than those in the general population [1]. More than ten million people live on prisons over the world [2] and study showed people in prisons were found to have higher prevalence of trauma history that would put them at high risk of posttraumatic stress disorder [3]. Post-traumatic stress disorder (PTSD) is a severe, disabling mental disorder which occur when a person experience traumatic events including combat, severe physical or sexual assault, a serious accident, torture, sudden unexpected death of a loved one, natural disasters or other threats [4] according to DSM-V [5]. The Global Burden of Disease 2000 study estimated burden of PTSD has increased to $0.6 \%$ of total global YLDs [6]. The most recent findings from world mental health (WMH) surveys on the global burden of mental disorders in 28 countries throughout the world indicated PTSD was among commonly occurring and severely disabling mental disorder and rated as $54.8 \%$ \& $41.2 \%$ disability in developed and developing countries respectively [7].

Persons involved in the criminal justice system and those with mental disorders are significantly at higher risk of trauma exposure and development of PTSD compared with the general population [8]. PTSD increases risk of criminal behavior partly through the use of substances to cope with the psychological and biological sequel of trauma exposure, moreover behavioral problems that are associated with their psychiatric conditions also place them at greater risk of committing rule violations and inappropriately imprisoned for relatively minor offences [9]. Study done in the rural United States, among 213 inmates reported that posttraumatic stress disorder was one of the most common disorders, with $33 \%$ meeting lifetime criteria and $21 \%$ of the participants meeting current (6-month) PTSD criteria [10].

A study done on 1055 male European long-term prisoners who were sentenced for at least five years by using posttraumatic diagnostic scale (PDS), found the highest prevalence among the Finland which was $27.8 \%$ followed by Croatian (20.6\%), England $(20.2 \%)$ and Germany (18.4\%) [11]. Another study done in State of South Paulo, Brazil in 2014, among 1,129 men and 617 women prisoners, reported $16.1 \%$ and $9 \%$ of 12 -month prevalence of PTSD among women and men, respectively [12].

Study done in South Africa on 193 prisoners, to determine the prevalence of serious mental disorders including PTSD in a prison population, indicated $9.8 \%$ of prevalence of post-traumatic stress disorder [13]. However, there is very limited study and to the knowledge of the researchers there is no published study done in this regard in Eastern Africa. Therefore, this study was designed to assess the prevalence of PTSD and associated factors among Prisoners of Nekemte town correctional center.

*Corresponding author: Shimelis Girma, Department of Psychiatry, Institute of Health, Jimma University, Ethiopia, Tel: +25911721438; E-mail: shimelisgirma@gmail.com

Received: August 30, 2018; Accepted: September 21, 2018; Published: September 18, 2018

Citation: Girma S, Fikadu T, Tadesse B (2018) Post-Traumatic Stress Disorder: The Case of Nekemte Town Correctional Center, West Ethiopia. J Psychiatry 21: 456. doi:10.4172/2378-5756.1000456

Copyright: $\odot 2018$ Girma S, et al. This is an open-access article distributed under the terms of the Creative Commons Attribution License, which permits unrestricted use, distribution, and reproduction in any medium, provided the original author and source are credited 


\section{Materials and Methods}

\section{Study design, study area and study subject}

An institution-based cross-sectional study design was employed. Study was conducted in Nekemte town correctional center from June 1-26, 2017. The town is situated in West of Ethiopia and covers a total area of 4,623 hectares. Administratively the town is divided into 13 Kebeles. Nekemte town correctional institution is established in 1967 E.C and currently the center has 1760 prisoners.

\section{Data collection instruments}

Data was collected by using structured questionnaire consisting demographic characteristics,criminal and substance histories, illness related factors as well as the PTSD Checklist-Civilian Version(PCL-C) and Life Events Checklist(LEC). PCL was developed by Frank Weathers and his colleagues at the National Center for PTSD in1993 [14]. It is a 17-item self-report PTSD screening instrument that corresponds to the key symptoms of PTSD applied generally for assessment of patients exposed to any forms of traumatic event. PCL is the most commonly used screening mechanisms for PTSD and has been found to be reliable and valid for screening purposes across numerous populations [15]. The PCL scales have 5-point (1-5) Likert scales range from 1(not at all) to 5 (extremely). Individual item scores were summed and the total score of 44 and above were considered to have PTSD. The PCL showed a sensitivity of .97 and a specificity of 0.87 [16]. Life Events check list traumatic life events questionnaire to obtain a more reliable and valid measure of traumatic events, consistent with PTSD DSM V criterion A1 [17].

\section{Participants}

Source populations were all prisoners in Nekemte town correctional center. Sample size was determined using single population proportion formula by considering the proportion of PTSD among prisoners $50 \%$ as there is no previous study, confidence level $95 \%, 5 \%$ margin of error. Thus, the sample size required for the study was 336 . Simple random sampling was used by using the list of prisoners as sampling frame.

\section{Statistical analysis}

Data was checked for completeness, edited, coded and entered into Epi data version 3.1 and exported to SPSS version 21.0 statistical software for analysis. Descriptive statistics such as mean, median, frequency and percentage was used and presented using charts and tables. Bivariable analysis was done and all explanatory variables which had association with the outcome variable with P-value less than 0.25 were included in multivariable analysis. Multi variable logistic regression analysis was employed to determine independent predictors. P-value less than 0.05 were used to declare statistical significance. Model fitness was assessed using hosmer and lemeshow test and it was found to be 0.75 . Multicollinearity was checked by variance inflation factor (VIF) and tolerance test. The result of VIF was found to be less than 2 while tolerance test was greater than 0.1 , which was within the normal limit.

\section{Results}

\section{Socio-demographic characteristics of respondents}

The study was conducted with response rate of $98.8 \%$. Three hundred eleven (93.7\%) were male participants whose age ranged from 16 to 84 year; nearly half $160(48.2 \%)$ of participants were unmarried; three fourth of the respondents $219(66.0 \%)$ were Oromo ethnic group and one fifth $68(20.5 \%)$ of respondents had migration history (Table 1 ).

\section{Clinical and substance use related characteristics}

The study revealed that $36(10.8 \%)$ of respondents had chronic medical illness, $52(15.7 \%)$ had history of family mental illness. Nearly one tenth $31(9.3 \%)$ had history of past mental illness. Similarly, the study revealed that almost half of study participants 168(50.6\%), more

\begin{tabular}{|c|c|c|c|}
\hline \multirow{2}{*}{ Variable } & \multirow{2}{*}{ Category } & \multicolumn{2}{|c|}{ Frequency } \\
\hline & & Number & Percent (\%) \\
\hline \multirow{2}{*}{ Sex } & Male & 311 & 93.7 \\
\hline & Female & 21 & 6.3 \\
\hline \multirow{4}{*}{ Age } & 16-25 Year & 156 & 47 \\
\hline & $26-36$ year & 117 & 35.2 \\
\hline & $37-50$ year & 40 & 12 \\
\hline & $>50$ year & 19 & 5.7 \\
\hline \multirow{3}{*}{ Marital status } & Married & 143 & 43.1 \\
\hline & Single & 160 & 48.2 \\
\hline & Other* & 29 & 8.7 \\
\hline \multirow{4}{*}{ Ethnicity } & Oromo & 219 & 66 \\
\hline & Amhara & 64 & 19.3 \\
\hline & Dawro & 32 & 9.6 \\
\hline & Others ${ }^{* *}$ & 17 & 5.1 \\
\hline \multirow{3}{*}{ Religion } & Muslim & 180 & 54.2 \\
\hline & Orthodox & 125 & 37.7 \\
\hline & Protestant & 27 & 8.1 \\
\hline \multirow{2}{*}{ Residence } & Rural & 106 & 31.9 \\
\hline & Urban & 226 & 68.1 \\
\hline \multirow{3}{*}{ Migration status } & Yes & 68 & 20.5 \\
\hline & No & 264 & 79.5 \\
\hline & Illiterates & 44 & 13.3 \\
\hline \multirow{3}{*}{ Educational status } & Grade 1-8 & 189 & 56.9 \\
\hline & Grade 9-12 & 72 & 21.7 \\
\hline & College and above & 27 & 8.1 \\
\hline Occupation before & Farmer & 84 & 25.3 \\
\hline \multirow{2}{*}{ Imprisonment } & Employed & 162 & 48.8 \\
\hline & Un employed & 86 & 25.9 \\
\hline Others * widowed, di & ${ }^{* *}$ kaffa, Gura & gre and $\mathrm{Ye}$ & \\
\hline
\end{tabular}

Table 1: Socio-demographic and economic characteristics of prisoners of Nekemte town correction center, West Ethiopia, 2017(n=332).

\begin{tabular}{|c|c|c|c|}
\hline \multirow{2}{*}{ Variable } & \multirow{2}{*}{ Category } & \multicolumn{2}{|c|}{ Frequency } \\
\hline & & Number & Percent (\%) \\
\hline \multirow{2}{*}{ Chronic medical illness } & Yes & 36 & 10.8 \\
\hline & No & 296 & 89.2 \\
\hline \multirow{2}{*}{ Family mental illness } & Yes & 52 & 15.7 \\
\hline & No & 280 & 84.3 \\
\hline \multirow{2}{*}{ Past or current mental illness } & Yes & 31 & 9.3 \\
\hline & No & 301 & 90.7 \\
\hline \multirow{2}{*}{ Past psychiatric hospitalization } & Yes & 24 & 7.2 \\
\hline & No & 308 & 92.8 \\
\hline \multirow{2}{*}{ Current psychiatric treatment } & Yes & 18 & 5.4 \\
\hline & No & 314 & 94.6 \\
\hline \multirow{2}{*}{ Alcohol use } & Yes & 73 & 22 \\
\hline & No & 259 & 78 \\
\hline \multirow{2}{*}{ Tobacco use } & Yes & 56 & 16.9 \\
\hline & No & 276 & 83.1 \\
\hline \multirow{2}{*}{ Khat use } & Yes & 168 & 50.6 \\
\hline & No & 164 & 49.4 \\
\hline \multirow{2}{*}{ Cannabis use } & yes & 20 & 6 \\
\hline & No & 312 & 94 \\
\hline
\end{tabular}

Table 2: Illness related and life time substance use history among prisoners of Nekemte town correction center, West Ethiopia, 2017 $(n=332)$. 
Citation: Girma S, Fikadu T, Tadesse B (2018) Post-Traumatic Stress Disorder: The Case of Nekemte Town Correctional Center, West Ethiopia. J Psychiatry 21: 456. doi:10.4172/2378-5756.1000456

Page 3 of 5

\begin{tabular}{|c|c|c|c|}
\hline \multirow{2}{*}{ Traumatic Event } & \multirow{2}{*}{$\begin{array}{c}\text { Number } \\
(\%)\end{array}$} & \multicolumn{2}{|c|}{ PTSD } \\
\hline & & Yes & No \\
\hline Natural disaster & $31(9.3 \%)$ & $25(80.6 \%)$ & $6(19.4 \%)$ \\
\hline Fire or explosion & $38(11.4 \%)$ & $31(81.6 \%)$ & $7(18.4 \%)$ \\
\hline Transportation accident & $85(25.6 \%)$ & $63(74.1 \%)$ & $22(25.9 \%)$ \\
\hline $\begin{array}{l}\text { Serious accident at work, home, or during } \\
\text { recreational activity }\end{array}$ & $29(8.7 \%)$ & $27(93.1 \%)$ & $2(6.9 \%)$ \\
\hline Exposure to toxic substance & $12(3.6 \%)$ & $11(91.7 \%)$ & $1(8.3 \%)$ \\
\hline Physical assault & $48(14.5 \%)$ & $41(85.4 \%)$ & $7(14.6 \%)$ \\
\hline Assault with a weapon & $45(13.6 \%)$ & $43(95.6 \%)$ & $2(4.4 \%)$ \\
\hline Sexual assault & $9(2.7 \%)$ & $8(88.9 \%)$ & $1(11.1 \%)$ \\
\hline $\begin{array}{l}\text { Other unwanted or uncomfortable sexual } \\
\text { experience }\end{array}$ & $10(3 \%)$ & $9(90.0 \%)$ & $1(10.0 \%)$ \\
\hline Combat or exposure to a war-zone & $14(4.2 \%)$ & $13(92.9 \%)$ & $1(7.1 \%)$ \\
\hline Captivity & $16(4.8 \%)$ & $14(87.5 \%)$ & $2(12.5 \%)$ \\
\hline Life-threatening illness or injury & $30(9 \%)$ & $27(90 \%)$ & $3(10 \%)$ \\
\hline Sever human suffering & $32(9.6 \%)$ & $25(78.1 \%)$ & $7(21.9 \%)$ \\
\hline A sudden, violent death & $34(10.2 \%)$ & $30(88.2 \%)$ & $4(11.8 \%)$ \\
\hline $\begin{array}{l}\text { Sudden, unexpected death of someone } \\
\text { close to you }\end{array}$ & $54(16.3 \%)$ & $43(79.6 \%)$ & $11(20.4 \%)$ \\
\hline $\begin{array}{l}\text { Serious injury, harm or death you caused to } \\
\text { someone else }\end{array}$ & $36(10.8 \%)$ & $30(83.3 \%)$ & $6(16.7 \%)$ \\
\hline Any other very stressful event or experience & $37(11.1 \%)$ & $31(83.8 \%)$ & $6(16.2 \%)$ \\
\hline
\end{tabular}

Table 3: Traumatic life events experiences among prisoners of Nekemte town correction center, West Ethiopia, 2017(n=332). than one fifth $73(22.0 \%)$ and more than half $56(16.9 \%)$ of respondents had khat, alcohol and tobacco use history at least once in their lifetime before imprisonment respectively (Table 2).

\section{Lifetime traumatic events and prevalence of PTSD}

Two in five 135(41\%) of the respondents were experienced at least one lifetime traumatic events and the events includes transportation accident, physical assault, natural disaster and sexual assault (Table 3). This study also revealed, one out of three (31\%) of study participants experienced post-traumatic stress disorder.

\section{Factors associated with PTSD}

Bi-variable Logistic regression analysis: Age, marital status ,migration status, educational status, type of current criminal, duration of sentence, no of previous incarceration, life time drinking alcohols , life time smoking tobacco, life time khat use, life time cannabis use showed significant association. However, educational status, no of previous incarceration, life time cannabis use, alcohol and tobacco use were not significant associated with PTSD during bi-variable analysis.

Multivariable logistic regression analysis: In the multivariate logistic regression analysis age category of 37-50, single/unmarried, history of migration and duration of sentence19-43 months were found to be independently significantly associated with PTSD. Study participants whose age category 37-50 were 2.82 times more likely

\begin{tabular}{|c|c|c|c|c|c|}
\hline \multirow{2}{*}{\multicolumn{2}{|c|}{ Variables }} & \multicolumn{2}{|c|}{ Post-traumatic Stress Disorder } & \multirow{3}{*}{$\begin{array}{c}\text { COR }(95 \% \mathrm{Cl}) \\
1\end{array}$} & \multirow{3}{*}{$\begin{array}{c}\text { AOR }(95 \% \mathrm{CI}) \\
1\end{array}$} \\
\hline & & \multirow{2}{*}{$\begin{array}{l}\text { No (n/\%) } \\
111(71.2)\end{array}$} & \multirow{2}{*}{$\begin{array}{c}\text { Yes (n/\%) } \\
45(28.8)\end{array}$} & & \\
\hline \multirow{4}{*}{ Age } & $16-25$ & & & & \\
\hline & $26-36$ & $79(67.5)$ & $38(32.5)$ & $1.086(0.67-1.76)$ & $1.32(0.73-2.38)$ \\
\hline & $37-50$ & $22(50.0)$ & $18(45.0)$ & $1.96(1.01-3.84)^{* *}$ & $2.82(1.31-6.06)^{* *}$ \\
\hline & $>51$ & $16(84.2)$ & $3(15.8)$ & $0.394(0.112-1.381$ & $0.85(0.2-3.597)$ \\
\hline \multirow{3}{*}{ Marital status } & Married & $104(72.7)$ & $39(27.3)$ & 1 & 1 \\
\hline & Single & $108(67.5)$ & $52(32.5)$ & $0.72(0.45-1.15)^{\star \star}$ & $1.86(1.06-3.27)^{\star *}$ \\
\hline & Others* & $16(55.2)$ & $13(44.8)$ & $1.11(0.7-1.77)$ & $0.744(0.28-2.02)$ \\
\hline \multirow{4}{*}{ Educational status } & Illiterate & $38(86.4)$ & $6(13.6)$ & $0.31(0.125-0.75)^{\star}$ & $0.39(0.15-1.03)$ \\
\hline & Grade 1-8 & $126(66.7)$ & $63(33.3)$ & $1.244(0.78-1.99)^{*}$ & $0.71(0.39-1.26)$ \\
\hline & Grade 9-12 & $45(62.5)$ & $27(37.5)$ & $1.43(0.83-2.463)$ & $1.12(0.37-3.31)$ \\
\hline & College \& above & $19(70.4)$ & $8(29.6)$ & 1 & 1 \\
\hline \multirow{2}{*}{ Migration } & No & $197(74.6)$ & $67(25.4)$ & 1 & 1 \\
\hline & Yes & $31(45.6)$ & $37(54.4)$ & $3.51(2.02-6.09)^{\star \star *}$ & $4.62(2.49-8.57)^{\star \star *}$ \\
\hline \multirow{4}{*}{ Type of current criminal } & Murder & $60(63.2)$ & $35(36.8)$ & $1.42(0.86-2.347)$ & $0.78(0.39-1.51)$ \\
\hline & Theft & $74(66.1)$ & $38(33.9)$ & $1.198(0.74-1.95)$ & $0.98(0.39-2.5)$ \\
\hline & Fight & $66(79.5)$ & $17(20.5)$ & $0.48(0.27-0.87)^{\star *}$ & $0.49(0.27-0.94)^{\star *}$ \\
\hline & Rape & $28(66.7)$ & $14(33.3)$ & 1 & 1 \\
\hline \multirow{4}{*}{ Duration of sentence(months) } & $0-18$ & $69(69.0)$ & $31(31.0)$ & 1 & 1 \\
\hline & $19-43$ & $54(80.6)$ & $13(19.4)$ & $0.46(0.24-0.89)^{\star *}$ & $0.422(0.2-0.88)^{* *}$ \\
\hline & $44-108$ & $60(69.0)$ & $27(31.0)$ & $0.98(0.58-1.67)$ & $1.24(0.61-2.49)$ \\
\hline & $>109$ & $45(57.7)$ & $33(42.3)$ & $1.89(1.12-3.19)^{\star}$ & $1.54(0.84-2.84)$ \\
\hline \multirow{2}{*}{ Life time Drinking alcohols } & No & $186(71.8)$ & $73(28.2)$ & 1 & 1 \\
\hline & Yes & $42(57.5)$ & $31(42.5)$ & $1.88(1.09-3.22)^{\star *}$ & $1.01(0.494-2.05)$ \\
\hline \multirow{2}{*}{ Life time smoking tobacco } & No & $196(71.0)$ & $80(29.0)$ & 1 & 1 \\
\hline & Yes & $32(57.1)$ & $24(42.9)$ & $1.837(1.02-3.31)^{\star *}$ & $1.47(0.71-3.04)$ \\
\hline \multirow{2}{*}{ Life time Khat use } & No & $117(65.0)$ & $63(35.0)$ & 1 & 1 \\
\hline & Yes & $111(73.0)$ & $41(27.0)$ & $0.67(0.43-1.09)^{*}$ & $0.619(0.37-1.04)$ \\
\hline \multirow{2}{*}{ Life time cannabis use } & No & $220(70.5)$ & $92(29.5)$ & 1 & 1 \\
\hline & Yes & $8(40.0)$ & $12(60.0)$ & $3.59(1.42-9.07)^{\star \star}$ & $1.64(0.54-5.0)$ \\
\hline
\end{tabular}

Table 4: Factors associated with PTSD among prisoners of Nekemte town correction center, West Ethiopia, 2017( $n=332)$. 
showing PTSD symptoms than age group of $16-25$ [AOR=2.82 (95\%CI, 1.31-6.06)]. The odds of PTSD on single/unmarried individuals were 1.86 times more likely than married $[\mathrm{AOR}=1.86$ (95\%CI,1.063.27)] and study participants who sentenced $19-43$ months were $58 \%$ less likely showed symptoms of PTSD compared with respondents sentenced 0-18 [AOR=0.49 (95\% CI, 0.27-0.94)] (Table 4).

\section{Discussion}

The current study revealed one in three $104(31 \%)$ prisoners in Nekemte town correction center had PTSD. Age group 37-50, single/ unmarried, migration history and duration of Sentence 19-43 months had significant association with PTSD.

The study showed the prevalence of PTSD among prisoners in Nekemte town correction center was $31 \%$. The finding of this study goes in line with the reports of study done in a rural Northeastern united states 33\% [10], Finland 27.8\% [11], Switzerland 27\% [18], Australia 26\% [19] and New York 30\% [20]. However the finding of the present study also higher than the study results in Chicago 21\% [21] South Africa 9.8\% [13] Iranian prisoners 17.4\% [10]. The probable reason for the difference might be use of differing screening instrument, difference in socio demographic characteristics of study population.

Result of this study revealed that participants age was found to be significantly associated with PTSD; respondents whose age category 37-50 were found to have likelihood of PTSD as compared to those 16-25 age range. There is a need to conduct further study with strong design to identify the relationship of PTSD with age while the possible explanation is young people in the aftermath of trauma can be more adaptable than older people. This may be because core beliefs of younger people are more likely to be challenged and potentially more changeable, whereas order's core beliefs are more resistant to change [22].

Based on the findings of this study, participants who had history of migration were 4.6 times more likely to be affected by PTSD than respondent with no migration history, which is in line with a study done in Sweden [23].The possible reasons might be, immigrants are particularly at risk for PTSD due to a history of multiple traumatic events associated with specific stressors. Moreover, severe post-migration living difficulties such as undermining of cultural identity, obstacles to employment, racial discrimination, poverty, disappointment in not achieving expectations and loneliness, can contribute to the onset/ worsening of a PTSD and to long term difficulties [24,25].

Study participants who sentenced 19-43 months were less likely showed symptoms of PTSD compared with respondents sentenced 0-18 months. This might be due to earlier periods of imprisonment may be more difficult for inmates in terms of adjustment, and so increased risk of violence during incarceration that most influences the likelihood of experiencing PTSD among incarcerated individuals [26]. The current study result is not compatible with study done in Iran which indicates prevalence of PTSD in prisoners with longer duration of imprisonment was higher than others. This effect can be explained by prison environment, type of crime, evaluation, and long isolation [27].

Overall, the study is the first of its kind in the country to determine the prevalence and associated Factors of PTSD among prison population. However, self-reported experiences of PTSD symptoms are subjected to recall or social desirability bias.

\section{Conclusion}

The result of the current study showed that one of three prisoners had PTSD in Nekemte town correctional center. Study participants whose age group 37-50, single/unmarried, those who had history of migration and duration of sentence 19-43 months were found to have statistical association with PTSD in the final model. Accordingly, the prison administration and concerned body should give an emphasis on way to provide mental health service for the prisoners and there is a need to conduct further study with strong design to look for the relationship between age and PTSD.

\section{Acknowledgement}

The authors would like to express their gratitude to local administrators, data collectors, and supervisors and study participants for their diligence and dedication in the collecting and inputting high quality data used in the study.

\section{Conflict of Interest}

None

\section{Reference}

1. WHO (2014) Regional office for Europe, Mental Health.

2. Walmsley R (2014) World Prison Population List, Eleventh edition. Inst Crim Policy Res 1-15.

3. CW H (1999) Prior abuse reported by inmates and probationers, Bureau of Justice Statistics Selected Findings, US Department of Justice.

4. Stein DJ, Seedat S, Iversen A, Wessely S (2007) Post-traumatic stress disorder: Medicine and Politics. Lancet 369: 139-44.

5. American Psychiatric Association (2013) Diagnostic and statistical manual of mental disorders (5th ed).

6. Ayuso-mateos JL (2001) Global burden of post-traumatic stress disorder in the year 2000 : Version 1 estimates. Global Bur Dis 1-6.

7. Kessler RC, Aguilar-gaxiola S, Alonso J, Chatterji S, Lee S, et al. (2011) The global burden of mental disorders: an update from the WHO World Menta Health (WMH) surveys. Epidemiol Psichiatr Soc 18: 23-33.

8. James DJ, Glaze LE (2006) Health Problems of Prison and Jail inmates Bureau of Justice Statistics Special Report, U.S. Department of Justice.

9. Chilcoat HD, Breslau N (1998) Posttraumatic stress disorder and drug disorders: Testing causal pathways. Arch Gen Psychiatry 55: 913-917.

10. Powell TA, Holt JC, Fonda KM (1997) The Prevalence of Mental Illness Among Inmates in a Rural State. Law Hum Behav 21: 427-438.

11. Dudeck M, Drenkhahn K, Spitzer C, Barnow S, Kopp D, et al. (2011) Traumatization and mental distress in long-term prisoners in Europe. Punish Soci 13: 403-423.

12. Quintana MI, Ribeiro WS, Andreoli SB, Blay SL, Geraldo J, et al. (2014) Prevalence of Mental Disorders among Prisoners in the State of Sao Paulo, Brazil. PLos One 9: e88836.

13. Naidoo S, Mkize DL (2012) Prevalence of mental disorders in a prison population in Durban, South Africa. J Psychiatry 15: 30-35.

14. Weathers FW, Litz, BT, Herman DS, Huska JA, Keane TM (1993) The PTSD Checklist: Reliability, validity, \& diagnositic utility. Annu Meet Int Soc Trauma Stress Stud San Antonio, TX

15. U.S. Department of Veteran's Affairs. National Center for PTSD: Assessments

16. Blanchard EB, Jones-Alexander J, Buckley TC, Forneris CA (1996) Psychometric properties of the PTSD Checklist (PCL). Behav Res Ther 34: 669-673.

17. Gray MJ, Litz BT, Hsu JL, Lombardo TW (1998) Psychometric Properties of the Life Events Checklist. Assessment 11: 330-341.

18. Urbaniok F, Endrass J, Noll T, Vetter S, Rossegger A (2007) Posttraumatic Stress Disorder in a Swiss offender population. Swiss Med Wkly137: 151-156.

19. Butler T, Allnut S (2003) Mental illness among New South Wales prisoners

20. Wolff N, Huening J, Shi J, Frueh BC (2014) Trauma Exposure and Posttraumatic Stress Disorder among Incarcerated Men. J Urban Health 91:707-719. 
Citation: Girma S, Fikadu T, Tadesse B (2018) Post-Traumatic Stress Disorder: The Case of Nekemte Town Correctional Center, West Ethiopia. J Psychiatry 21: 456. doi:10.4172/2378-5756.1000456

Page 5 of 5

21. Ruzich D, Reichert J, Lurigio AJ (2014) Probable posttraumatic stress disorder in a sample of urban jail detainees. 10: 455-463.

22. Calhoun LG, Cann A, Tedeschi R, McMillan J (2000) A correlational test of the relationship between posttraumatic growth, religion, and cognitive processing. J Trauma Stress 13: 521-527.

23. Kristiansson M, Sumelius K, Sondergaard HP (2004) Post-traumatic Stress Disorder in the Forensic Psychiatric Setting. J Am Acad Psychiatry Law 32: 399-407.

24. Steel Z, Momartin S, Silove D, Coello M, Aroche J, et al. (2011) Two year psychosocial and mental health outcomes for refugees subjected to restrictive or supportive immigration policies. Soc Sci Med 72: 1149-1156.

25. Fortuna LR, Porche MV, Alegria M (2008) Political violence, psychosocia trauma, and the context of mental health services use among immigran Latinos in the United States. Ethn Heal 13: 435-463.

26. Hayes LM (1995) Prison suicide: An overview and guide to prevention.

27. Sepehrmanesh Z, Ahmadvand A, Akasheh G, Saei R (2014) Prevalence of Psychiatric Disorders and Related Factors in Male Prisoners. Iran Red Crescent Med J 16: e15205. 